\title{
Paschen Problems in Large Coil Systems
}

\author{
Christian Lange, Jürgen Baldzuhn, Stefan Fink, Reinhard Heller, Markus Hollik, Walter H. Fietz
}

\begin{abstract}
When a breakdown of the thermally insulating vacuum occurs in an energized high power coil system (e.g. a leakage of the He-cooling system or to the surrounding air) the coils warm up and have to be discharged fast to avoid destruction. Due to the coil inductance and the necessary discharge time, a high voltage is produced in the coil and the feeder system. Therefore an unspecified pressure coincides with the occurrence of a high voltage at the coil and feeder system.

It is well known that under these conditions arcing can occur at a magnet when it is not perfectly insulated even for voltages $<$ $1 \mathrm{kV}$ (Paschen-effect). The gas dependent breakdown voltage minimum occurs typically in the range of some $100 \mathrm{~V}$ at a pressure value that depends from geometry and temperature. For lower and higher pressures the breakdown voltage is increasing.
\end{abstract}

For a high power magnet system an insulation is necessary that can withstand high voltage in the $10 \mathrm{kV}$ range although any possible pressure is applied to the system. Usually a pressure independent solid insulation is used to solve this requirement.

In order to test the reliability of this electrical insulation under all pressure conditions, a so-called Paschen test has to be performed. This Paschen test is a high voltage test with pressures varying between good vacuum and ambient pressure.

In this paper examples for insulation failures on large coils found with Paschen testing are given. In a series of experiments with samples that have been prepared with intended insulation faults the necessity of Paschen testing is demonstrated to identify insulation problems that are not visible under good vacuum or ambient pressure.

Therefore, a Paschen-test is also a useful high voltage diagnostic tool to localize insulation faults in solid insulated magnets.

Index Terms - High voltage techniques, Insulation, Paschen testing, Vacuum breakdown

\section{INTRODUCTION}

$\mathrm{H}$ igh voltages are generated in coils during a fast current change, for example at a fast discharge of a superconducting coil. The electrical insulation of the coil has to withstand this voltage. At normal conditions the coil is

Manuscript received 09 September 2011. This work, supported by the European Communities under the contract of Association between EURATOM and Karlsruhe Institute of Technology, was carried out within the framework of the European Fusion Development Agreement. The views and opinions expressed herein do not necessarily reflect those of the European Commission.

Christian Lange, Stefan Fink, Reinhard Heller, Walter H. Fietz are with the Karlsruhe Institut for Technology, Institute for Technical Physics, Karlsruhe, Germany (corresponding author phone: +497216086480; e-mail: c.lange@kit.edu).

Jürgen Baldzuhn are with the Max-Planck-Institut für Plasmaphysik, Teilinstitut Greifswald, Greifswald, Germany surrounded by vacuum for thermal insulation. This vacuum can be also a good electrical insulation (depending on setup and voltage excitation).

In case of a vacuum breakdown, the coil has to be fast discharged to avoid a quench. In this moment a high voltage occurs at the coil together with an undefined gas pressure. This can lead to an electrical breakdown.

For good vacuum and very low pressures the dielectric strength of an arrangement depends on the electrodes (geometry, roughness, material, etc.). For higher gas pressures the dielectric strength of a gas depends on the product of the gas pressure $p$ times the distance between the electrodes $d$.

This dependence is known as the Paschen's Law. Fig. 1 shows a Paschen curve for air [1], [2].

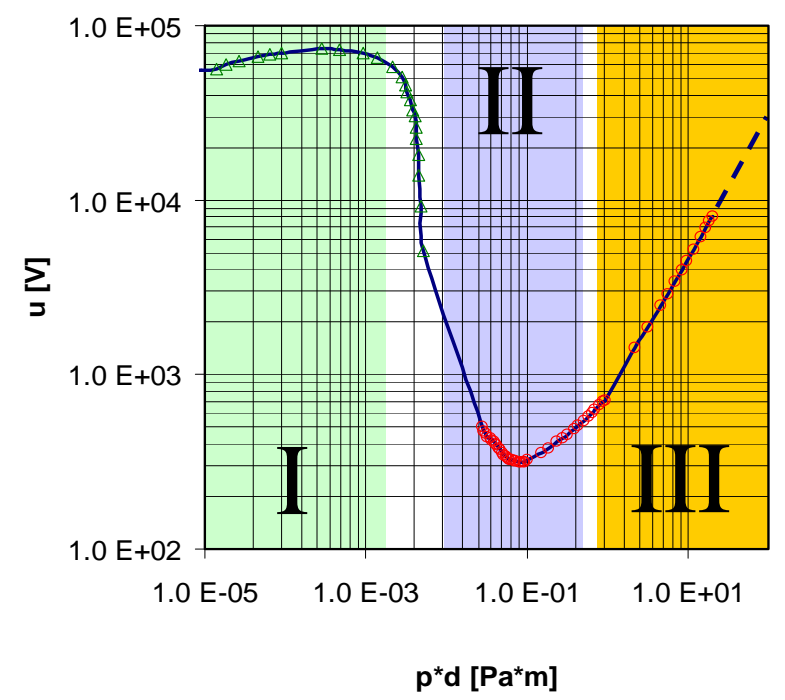

Fig. 1: Paschen curve for air

The Paschen curve shows the breakdown voltage as a function of $p \cdot d$ for a constant temperature.

For very low values of $p \cdot d$ (range I) the dielectric strength is constant and depends mainly on the surface conditions of the electrodes. At high values of $p \cdot d$ (range III) the breakdown voltage is relatively high and increases approximately linear with $p \cdot d$. In between (range II) the breakdown voltage has a distinct minimum with values down to $350 \mathrm{~V}$ at $0.73 \mathrm{~Pa} \cdot \mathrm{m}$ for air and $155 \mathrm{~V}$ at $5.3 \mathrm{~Pa} \cdot \mathrm{m}$ for He under worst case conditions [3]. This minimum is called Paschen minimum.

A complete encapsulation of all high voltage active parts by solid insulation ensures a reliable high voltage operation independently of the surrounding vacuum conditions. A device manufactured according to such a principle is called Paschen tight. 


\section{PASCHEN - PROBlem AT ITER- TOROIDAL FIELD MODEL COIL (TFMC)}

For the test of the ITER-TFMC coil a high voltage test was performed during the pump-down of the cryostat. The coil has a solid electrical insulation that was tested at ambient pressure and under good vacuum. However at $7.5 \mathrm{kV}$ a breakdown occurred. Additional tests showed that the breakdown voltage at $40 \mathrm{~Pa}$ was only $1.25 \mathrm{kV}$.

In order to find the failure, cameras were installed within the cryostat. A flash was observed at two positions, but they could not be investigated in more detail as long as the coil was in the cryostat. After the coil was removed from the cryostat, it turned out, that one flash was a reflection. At the other position a plastic tape (Tedlar) was found in the insulation that had not been remove during the manufacturing [4].

The coil was not Paschen tested before installation therefore the failure was not detected and could not be fixed.

\section{PASCHEN TESTING OF A W7-X CURRENT LEAD}

The Karlsruhe Institute of Technology (KIT) is responsible for the design, construction and testing of current leads for the Stellerator Wendelstein 7-X [5].

The current leads have a solid insulation of glass fiber reinforced plastic (GRP), covered with a grounded conductive paint. The measuring cables have a polyimide isolation with surrounding ground screen.

A $13 \mathrm{kV}$ DC HV- test at ambient pressure and under good vacuum showed no failure. But for pressures between $100 \mathrm{~Pa}$ and $5 \cdot 10^{3} \mathrm{~Pa}$ a breakdown occurs on the experimental setup for voltages lower than $5 \mathrm{kV}$ (Fig. 2)

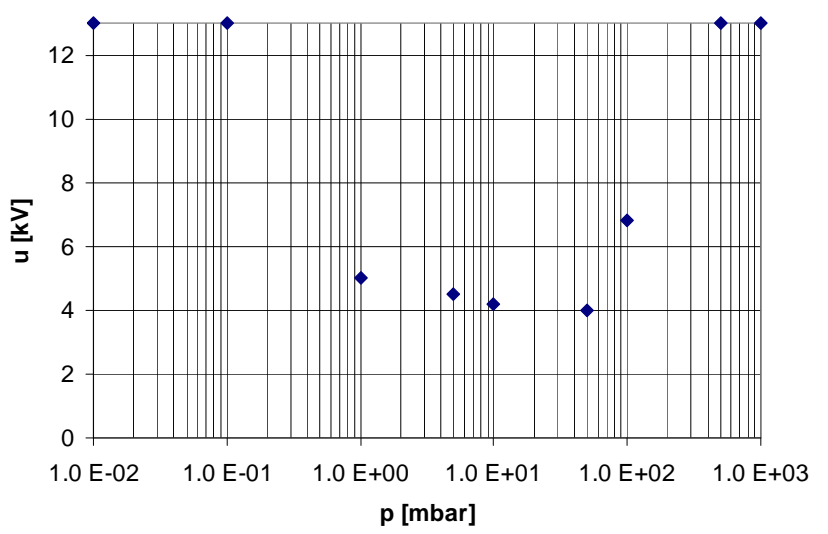

. Fig. 2: Measured isolating voltage (DC) of the complete setup

There have been several attempts to find the insulation failure:

- Cameras were installed within the cryostat, but only secondary effects have been observed. The main arc was inside the conductive paint.

- To find the failure at ambient pressure, neon was used as a surrounding gas, because it has a lower breakdown voltage than air.

- Separate vacuum test chambers have been used to generate a local Paschen-minimum for parts of the current leads, in order to localize the failure position.
- The grounded conductive paint was segmented in electrical insulated parts. One of these usually grounded parts was connected to high voltage, too which gives no flashover even if there is a insulation defect in this part. By this method the segmented parts were tested sequentially to identify the defective part.

For the experimental setup the isolation failure was found with the last method. A casted measuring cable joint was not Paschen tight. (Fig. 3).
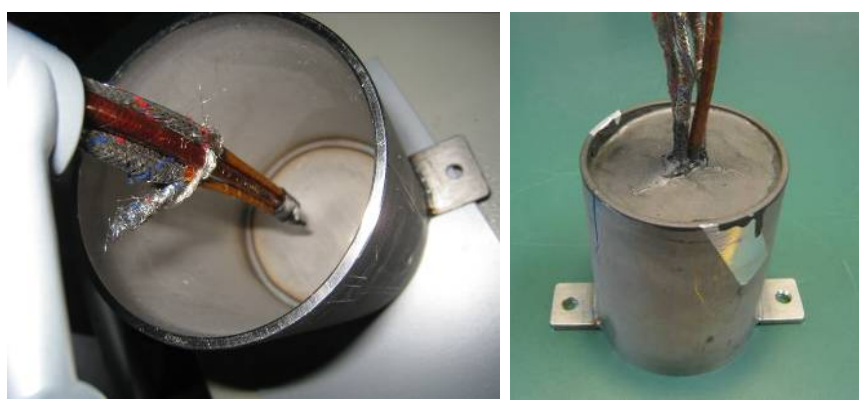

Fig. 3: Left side: Measuring cables and casting mold of the connecting piece before cast in. Right side: Not Paschen tight connecting piece after cast in, painted with conductive paint.

After identifying the failure the connection was fixed and the test could start.

\section{TeStS WITH INTENDED PASCHEN - FAILURES}

\section{A. Paschen - failure I}

A copper wire (diameter $3.6 \mathrm{~mm}$ ) was insulated by two layers of self-sealing heat shrinking tube (each $0.7 \mathrm{~mm}$ thick). A thin PVC tube (inner diameter $1.5 \mathrm{~mm}$ ) was placed between the layers, that simulated a crack or gap in the insulation (like the not well glued connection of two glass reinforced plastic pieces).

For the first and second test series the tube was $7.5 \mathrm{~cm}$ and $10 \mathrm{~cm}$ long, respectively. One end of the tube was located at the copper wire, the other end outside of the isolation. (Fig. 4 and Fig. 5).

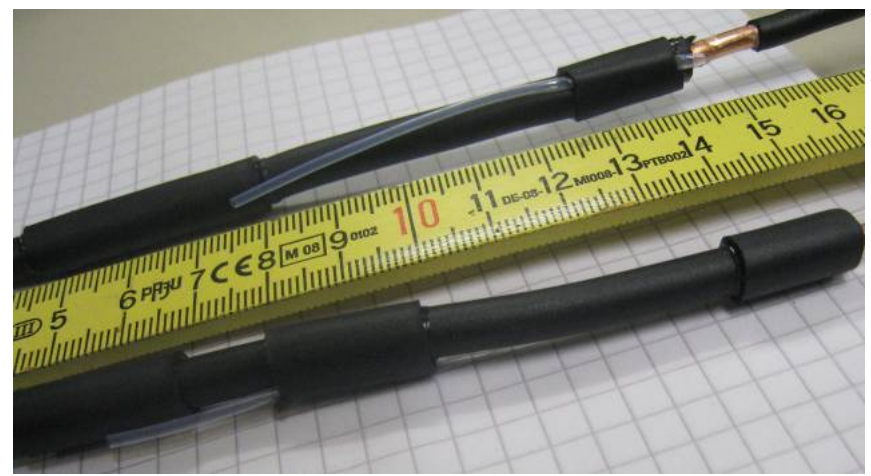

Fig. 4: Bare copper wire (right side), inner layer of heat shrinking tube and PVC-Tube, still without the outer layer of heat shrinking tube 


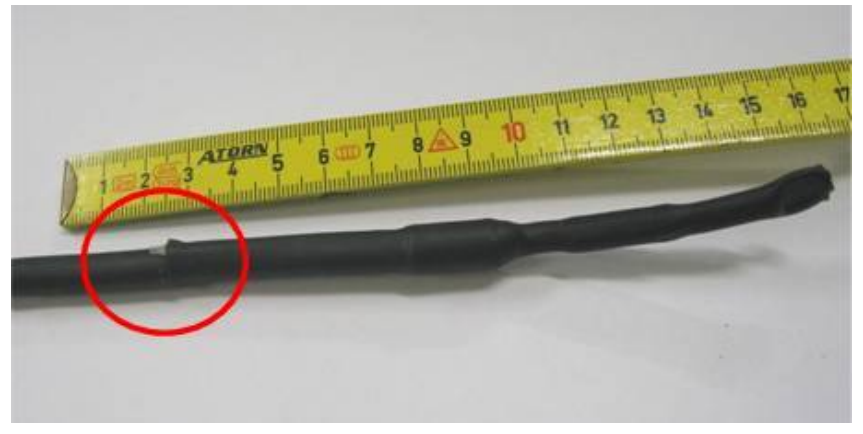

Fig. 5: Test object with outer layer of heat shrinking tube, outer end of the PVC-tube is free (on the left side)

This experimental setup was installed in a grounded vacuum vessel and the copper wire was connected to high voltage line. After the pressure was reduced to approx. $1 \mathrm{~Pa}$, the pressure was raised in steps and at different pressure ratings the DC breakdown voltage from copper wire to ground was measured.

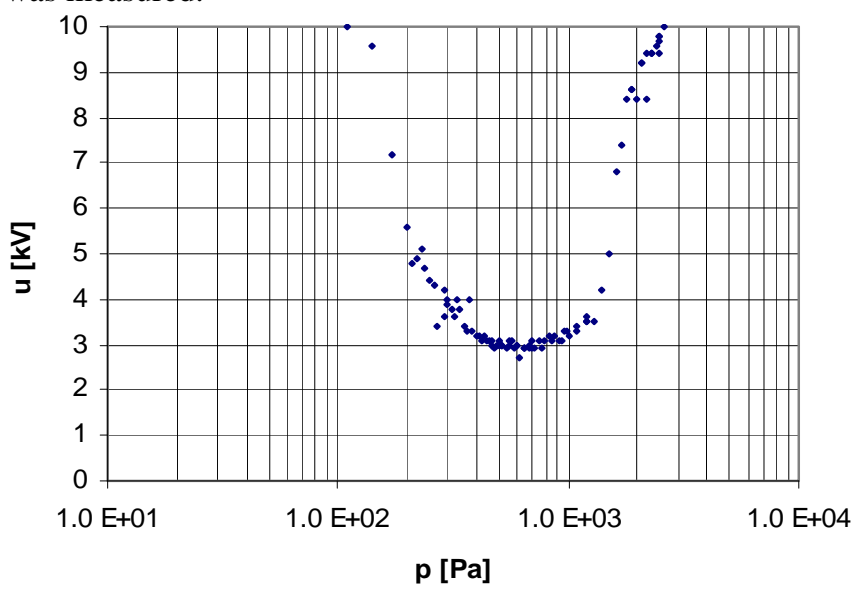

Fig. 6: The measured breakdown voltage (DC) of the simulated failure with the $7.5 \mathrm{~cm}$ PVC - tube without grounded shield as a function of gas pressure.

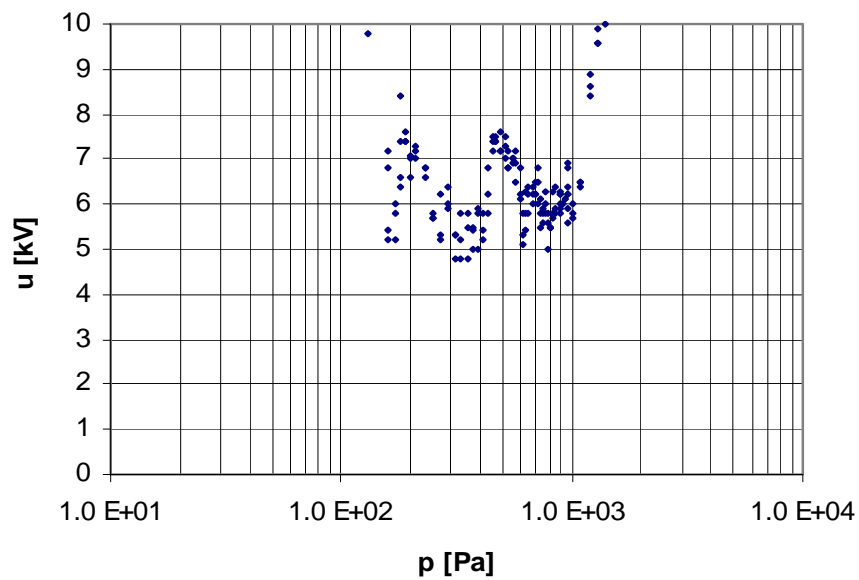

Fig. 7: The measured breakdown voltage (DC) of the simulated failure with the $10 \mathrm{~cm}$ PVC - tube without grounded shield as a function of gas pressure.

At pressures below $100 \mathrm{~Pa}$ and above $3000 \mathrm{~Pa}$ the setup is able to withstand at least $10 \mathrm{kV}$. For pressures between $100 \mathrm{~Pa}$ and $3000 \mathrm{~Pa}$, sometimes breakthroughs occurred at voltages down to $3 \mathrm{kV}$ (Fig. 6 and Fig. 7).

As expected no distinct Paschen minimum can be observed it these high voltage tests. The arc starts at the inner end of the PVC-tube and flashes over from the outer end to a spot at the wall of the vacuum vessel. This spot moves and changes the length of the discharge, depending on the pressure of the gas. So the product of gas pressure times distance is constant for a wide range of pressures and the breakthrough voltage stays constantly low.

Anyhow the Paschen minimum is far away from the ideal value, due to the not ideal electrodes, inhomogeneous electrical field and the possibility of a surface discharge.

For an additional test the outer insulating heat shrinking tube was completely wrapped in aluminum tape to simulate a grounded coating. The end of the PVC-Tube was covered, too and the aluminum tape was grounded.

This test simulated a Paschen - failure in a solid insulation between the live parts and an outer grounded shield.

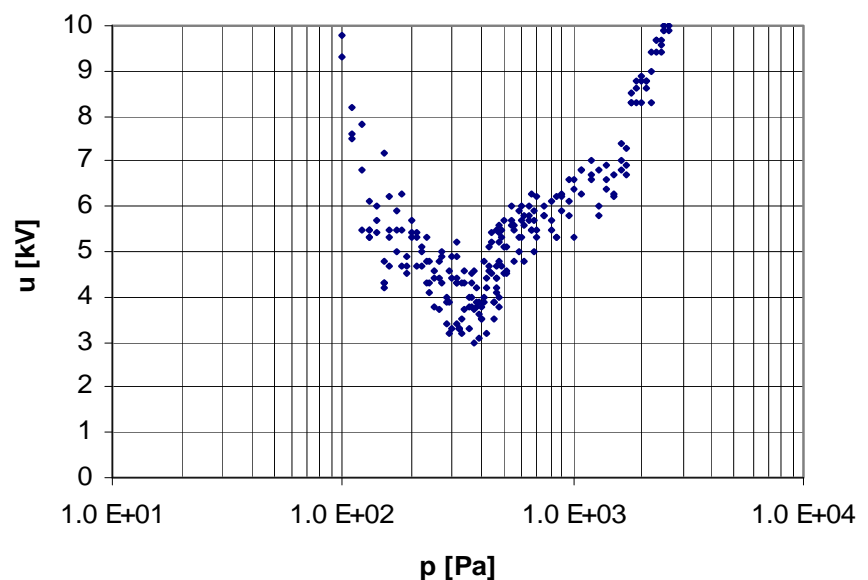

Fig. 8: The measured breakdown voltage (DC) of the simulated failure with the $7.5 \mathrm{~cm}$ PVC - tube with grounded aluminum tape.

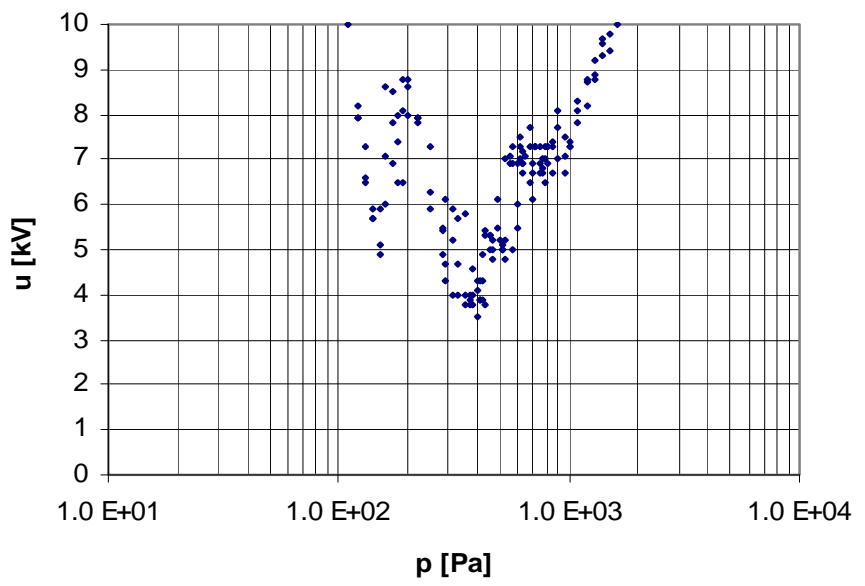

Fig. 9: The measured breakdown voltage (DC) of the simulated failure with the $10 \mathrm{~cm}$ PVC - tube with grounded aluminum tape.

At this test the length of the breakthrough is limited through the length of the PVC - tube. Nevertheless there is no clear Paschen minimum but a smaller pressure range for the minimum voltage as in the previous test where the end of the PVC-tube was open (Fig. 8 and Fig. 9).

Again the Paschen minimum is far away from the ideal value. 


\section{B. Paschen - failure (II)}

The end of a copper wire with a diameter of $3.6 \mathrm{~mm}$ was cast in a disk made of resin. The wire itself was insulated by a thin coat of cast resin and two additional layers of self-sealing heat shrinking tube ending at the disk. An intended failure was produced in the wire insulation at the transition to the disk by bending. This experimental setup was built into a grounded vacuum vessel and the copper wire was connected to high voltage (see Fig 10).

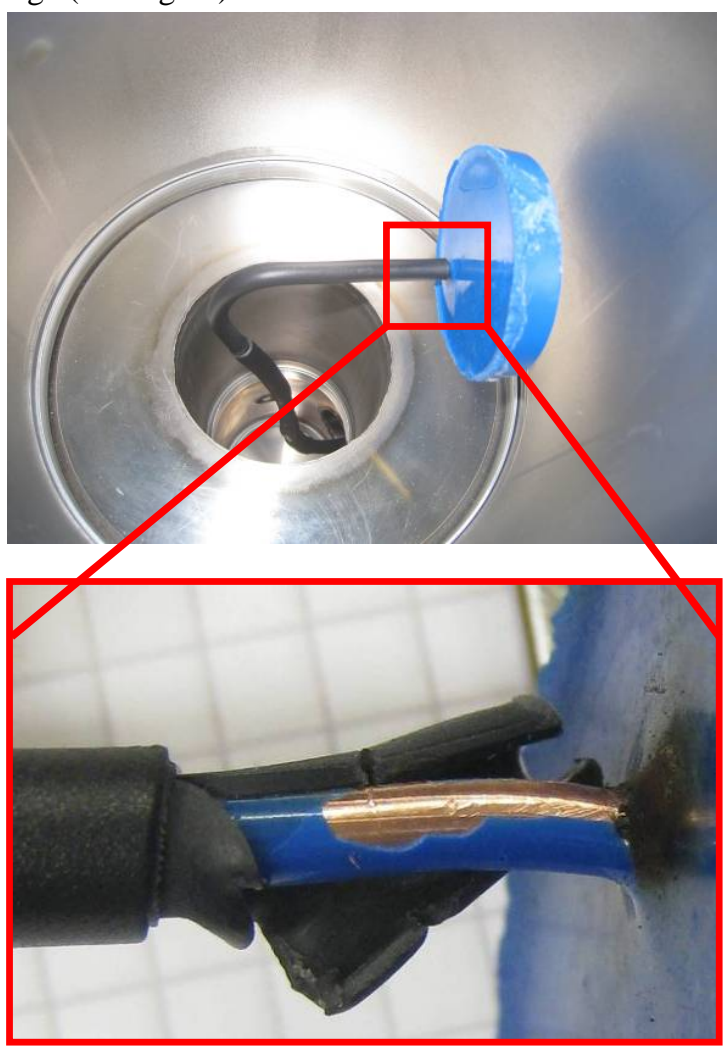

Fig. 10: Test object in vacuum vessel (top) and the failure at the test object (bottom) after test, the heat shrinking tube and parts of the resin were removed

At a pressure lower than $2 \mathrm{~Pa}$ or higher than $4 \cdot 10^{4} \mathrm{~Pa}$ the isolation of the wire is able to withstand at least $30 \mathrm{kV}$. For a pressure between $40 \mathrm{~Pa}$ und $200 \mathrm{~Pa}$ a breakdown occurs at a test voltage of about $2 \mathrm{kV}$ (Fig. 11).

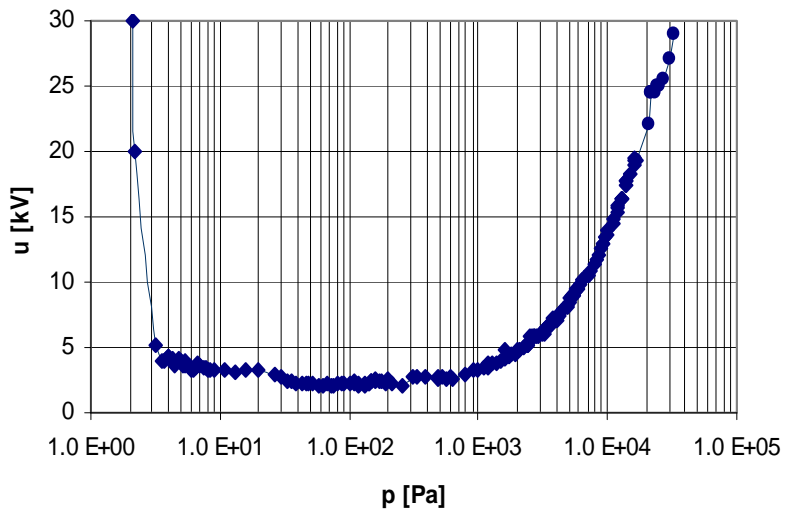

Fig. 11: The measured breakdown voltage (DC) of the simulated failure II as a function of gas pressure.
Like during the first test without outer grounded shield, the path of the electric arc is changed substantially, if pressure changes. The product of $p \cdot d$ remaines constant for a wide range and the breakthrough voltage remains constantly low. The electric arc does not use every time the shortest path. For example at $60 \mathrm{~Pa}$ (Fig. 12) the discharge flashs over to the side wall of the vacuum vessel (long way) and at $1.8 \cdot 10^{4} \mathrm{~Pa}$ (Fig. 13) the discharge flashs over to the bottom (short way).

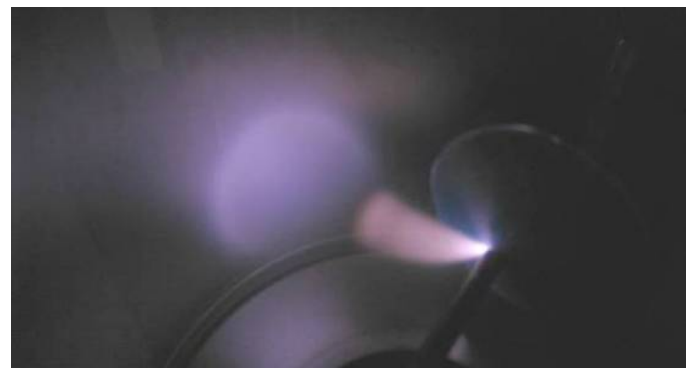

Fig. 12: The electric arc at $60 \mathrm{~Pa}$

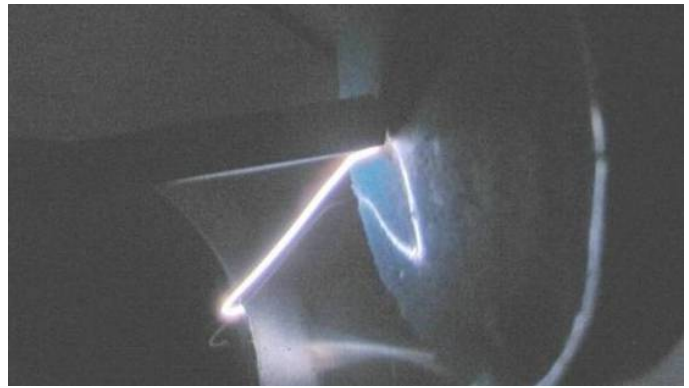

Fig. 13: The electric arc at $1.8 \cdot 10^{4} \mathrm{~Pa}$

\section{CONCLUSION}

Complete encapsulation of all live parts with solid electrical insulation is needed to avoid electrical breakdowns in case of a loss of vacuum.

Successful high voltage tests at ambient pressure and under good vacuum do not proof sufficient dielectric strength of a solid insulation. A gap or crack in the insulation can be insulated by air at ambient pressure or by vacuum. However, for the pressure ranges in between a breakdown can occur at relatively low voltages around $1 \mathrm{kV}$.

A single high voltage test at a pressure calculated from the theoretical Paschen-minimum is not reasonable, because of the undefined path of the electric arc. So systematic Paschen tests over a wide range of pressure are essential to find hidden isolation problems.

\section{REFERENCES}

[1] R.V. Latham, High Voltage Vacuum Insulation. London: Academic Press Limited, 1995, p. 40

[2] B. Gänger, Der elektrische Durchschlag in Gasen. Berlin: $\quad$ SpringerVerlag, 1953, p. 176-177.

[3] A. Küchler, Hochspannungstechnik. Berlin: Springer-Verlag,, 2005, p. 168

[4] A. Ulbricht at al., Fusion Engineering and Design 73 - The ITER toroidal field model coil project. Elsevier, 2005, p. 310

[5] W.H. Fietz, R. Heller, A. Kienzler and R. Lietzow, High Temperature Superconductor Current Leads for WENDELSTEIN 7-X and JT-60SA. IEEE Trans. on Appl. Supercond. vol 19 no 3 (2009), 2202-2205 